\title{
Review of Green Polymer Nanocomposites
}

\author{
Samson O. Adeosun ${ }^{1}$, G. I. Lawal ${ }^{1}$, Sambo A. Balogun ${ }^{1}$ and \\ Emmanuel I. Akpan ${ }^{2, *}$
}

Department of Metallurgical and Materials Engineering, University of Lagos, Lagos, Nigeria

2 Department of Materials and Production Engineering, Ambrose Alli University, Ekpoma, Nigeria

*Corresponding Author: emma_eia@yahoo.com

\begin{abstract}
:
Recently, attention has been drawn to the use of bio-reinforced composites in automotive, construction, packaging and medical applications due to increased concern for environmental sustainability. Green polymer nanocomposites show unique properties of combining the advantages of natural fillers and organic polymers. Plant fibers are found suitable to reinforce polymers. They have relatively high strength and stiffness, low cost of acquisition, low density and produce low $\mathrm{CO}_{2}$ emission. They are also biodegradable and are annually renewable compared to other fibrous materials. Organic polymers on the other hand, are desirable because they are either recyclable or biodegradable without causing environmental hazards. This paper reviews current research efforts, techniques of production, trends, challenges and prospects in the field of green nanocomposites.
\end{abstract}

Keywords: bio-reinforced composites; organic polymers; plant fibers; mechanical properties; environmental friendly 


\section{INTRODUCTION}

Research efforts are geared to the development and application of environmentally friendly and sustainable bio-reinforced composites for use in automotive, construction, packaging and medical fields. It has been reported [1,2] that addition of nanoparticles to base polymers confer improved properties that make them usable in automotive, construction and medical areas. Properties which have been shown to improve substantially are mechanical properties (e.g., strength, elastic modulus and dimensional stability), thermomechanical properties and permeability (e.g., gases, water and hydrocarbons). Others are thermal stability and heat distortion temperature, flame retardancy and smoke emissions, chemical resistance, surface appearance, physical weight and electrical conductivity. Nanocomposite is a class of composites in which the dimensions of the reinforcing material are in the order of nanometers. Because of this nanometer size characteristic, nanocomposites possess superior properties than the conventional composites due to maximizing the interfacial adhesion.

In the past, major interest has been in the use of synthetic materials such as aliphatic polyesters, aliphatic-aromatic polyesters, polyvinyl alcohols, polyesteramides, polystyrene, nanoclays, glass and carbon fibers and carbon nanotubes etc for the production of nanocomposites. The use of these materials, however, present great challenges [3-5]. These include shortage of the organic compounds due to declining oil and gas resources, increasing oil and gas prices. Other effects include environmental concerns for their degradation or incineration and global warming, uneconomical costs and cross contaminations in their recycling and consumer toxicity risks [6-10]. These concerns gave birth to the quest for materials that can overcome these challenges and maintain the required properties for the various applications.

The use of polymer composites from renewable sources has advantages over synthetic sources, particularly as a solution to the environmental problems generated by plastic waste [11]. They offer alternatives to maintaining sustainable development of economic and ecologically attractive technology [12]. Green composites is today widely researched because of the need for innovations in the development of materials from biodegradable 
polymers, preservation of fossil based raw materials, complete biological degradability and reduction in the volume of carbon dioxide release into the atmosphere. Application of agricultural resources (wastes and products) for the production of green materials are some of the reasons why green composites have attracted tremendous research interests [12]. The use of these biocomposites is expected to improve manufacturing speed and recycling with enhanced environmental compatibility [11].

\section{GREEN POLYMER}

Materials are said to be 'green' when they are biodegradable and renewable. The major attractions about green composites are that they are environmentally friendly, fully degradable and sustainable in every way. At the end of their service life they can be easily disposed of or composted without harming the environment. The challenge of green composite involves basically the challenge of obtaining 'green' polymers that are used as matrix for the production of the composites. Polymer is said to be green when it possesses environmentally favorable properties such as renewability and degradability. Biodegradation implies degradation of a polymer in natural environment that includes changes in the chemical structure, loss of mechanical and structural properties and changing into other compounds that are beneficial to the environment [6,11]. Polymers from natural sources (such as starch, lignin, cellulose acetate, poly-lactic acid (PLA), polyhydroxylalkanoates (PHA), polyhydroxylbutyrate (PHB), etc.) and some synthetic sources (aliphatic and aromatic polyesters, polyvinyl alcohol, modified polyolefins etc.) that are degradable are classified as biopolymers [11,13]. However, those from synthetic sources are not renewable and therefore do not conform wholly to the concept of renewability and degradability. A number of natural and other degradable polymers have been used in green composites and some of these are discussed below.

\subsection{Thermoplastic Starch Based Composites}

Earlier researches of thermoplastic starch based composites focused on the use of plasticized starch as matrix for green nanocomposites. De Carvalho et al. [14] first reported the use of thermoplastic starch for the production of composites by melt 
intercalation in twin screw extruder. The composites were prepared with regular cornstarch plasticized with glycerin and reinforced with hydrated kaolin. The study recorded significant increase in the tensile strength from 5 to $7.5 \mathrm{MPa}$ for the composite with 50 phr clay composition. The modulus of elasticity increased from 120 to $290 \mathrm{MPa}$ while the tensile strain at break decreased from 30 to 14\%. The maximum value for the modulus of elasticity observed and the tensile strength corresponded to the maximum quantity of clay that was incorporated in the matrix. Above which the authors noted that increase in the amount of filler increases the fragility of the composite.

Pandey and Singh [15] varied the sequence of addition of plasticizers to determine the effect of plasticizers on the mechanical and structural properties of resulting composites using solution method. Thermal stability, mechanical properties and water absorption studies were conducted to measure the material properties whereas FT-IR spectroscopy was used to study the microdomain structure of composites. It was deduced that the sequence of addition of components (starch/plasticizer (glycerol)/clay) had a significant effect on the nature of composites formed and consequently the properties were altered with no well established sequence to determine appropriate process method for the composites. The filler dispersion was found to become highly heterogeneous and the more brittle when starch was plasticized before filling with clay. The modulus of composites increased significantly for all compositions relative to the unfilled matrix, irrespective of the method of preparation. The authors posited that improvement in all the properties of the resulting composites could be achieved by better dispersion of the clay filler and not necessarily on varying the sequence of addition of plasticizers. Subsequently, Guan and Hanna [16] modified the starch with acetate and produced biocomposites with cellulose fibers. Starch acetates with degrees of substitution (DS) of 1.68 and 2.3 prepared from $70 \%$ amylose corn starch were extruded with 10\%, 20\% and $30 \%(\mathrm{w} / \mathrm{w})$ cellulose and 20\% (w/w) ethanol in a twin screw extruder at 150, 160 and $170{ }^{\circ} \mathrm{C}$ barrel temperatures and 170, 200 and $230 \mathrm{rpm}$ screw speeds. Results of X-ray diffraction showed losses in the crystallinity of starch and cellulose. FTIR spectra revealed that functional groups and chemical bonds were maintained after extrusion. The Melting temperatures of the composites were observed to change significantly when higher DS starch acetate were used. Experimental variables such as cellulose content, 
barrel temperature and screw speed have profound effect on thermal, physical and mechanical properties of extruded foams. For the extruded starch foams, thermal properties were strongly related to blend composition, barrel temperature and screw speed. $T_{g}$ and $T_{m}$ of the extruded foams decreased as cellulose content increased. The author noted that as barrel temperature and screw speed increased, Tg and Tm increased initially and then decreased when barrel temperature and screw speed were higher than $160{ }^{\circ} \mathrm{C}$ and $200 \mathrm{rpm}$ respectively. The Authors posited that Barrel temperature serve as an index of the thermal energy applied to the blends whereas screw speed indication of the mechanical energy applied to the blends.

Further study by Kumar and Singh [17] was done through starch modification by photoinduced cross linking. Composite films were made from the aqueous dispersions of starch with microcrystalline cellulose using glycerol as plasticizer and irradiated under ultraviolet (UV) light using sodium benzoate as photo-sensitizer via casting. Young's modulus of composites reinforced with 5, 10 and $15 \mathrm{wt} \%$ which were irradiated for 30 mins improved by $72.41 \%, 42.5 \%$ and $32 \%$ respectively, when compared to control samples.

The elongation (\%) values were found to decrease with increasing cellulose fiber content and time of photo-irradiation. Other researches on the use of thermoplastic starch without further modification (i.e., changes in experimental conditions) include the work of Lu et al. [18], Ma et al. [19], Svagan [20], Famá et al. [21], Kaushik et al.[22], Liu et al. [23], Guimarães et al. [24] and Kaith et al.[25]. These studies reported significant increase in tensile and thermal properties of thermoplastic starch when reinforced with nanofibers.

\subsection{Poly Lactic Acid Based Composites}

Ogata et al. [26] in their study prepared nanocomposites using poly lactic acid (PLA). PLA/ organically modified clay (OMLS) blends were made by dissolving the polymer in hot chloroform in the presence of dimethyl distearyl ammonium modified MMT (2C18MMT). X-ray diffraction results of PLA/MMT show that the silicate layers 
forming the clay could not be intercalated in the PLA/MMT blends when prepared by the solvent-cast method. The clay existed in the form of tactoids with several stacked silicate monolayers. The formation of geometrical structures in the blends was attributed to the tactoids, which led to the formation of superstructures in the thickness of the blended film. This could lead to a structural feature that promotes increase in the Young's modulus of the hybrid. A series of nanocomposites using PLA were reported by Sinha et al. [27-32], Yamada et al. [33], Maiti et al. [34], Paul et al. [35], Lee et al. [36] and Chang et al. [37]. These studies revealed that nanocomposites prepared with PLA had improved mechanical, thermal and impact properties. Bondeson and Oksman [38] used commercial PLA as the matrix with cellulose whiskers treated with anionic surfactant (5, 10 and $20 \mathrm{wt} \%)$ as reinforcement. The compounded materials were extruded in three steps with pelletizing between the first and the second steps. Extruded nanocomposites were compression moulded and characterized. The tensile strength and elongation at break decreased for this composite compared to PLA. This lack of improvement in the mechanical properties of the composite was attributed to poor adhesion between the fiber and the matrix which is directly related to the nature of the fiber and the type of mechanical treatment given.

Studies on the thermal, mechanical and morphological properties of PLA-based composites have been reported by Lee et al. [39]. Composites were prepared by melt compounding and injection molding. Thermal degradation, thermal transition, morphological, and mechanical properties of the composites were evaluated. Tensile modulus of the composite increased from 62.5 to $169.5 \%$ contrary to the earlier studies where no improvement was recorded. More recently, nanocomposites of PLA with a compatibilizer and cellulose fibrils have been developed by Qu, et al. [40]. Bleached wood pulp was used as the fiber and commercial grade PLA as the matrix. A chemomechanical method was used to prepare cellulose nanofibrils dispersed uniformly in an organic solvent. Poly ethylene glycol (PEG) was added to the matrix as a compatibilizer to improve the interfacial bonding/adhesion between the matrix and the fiber. The composites were obtained by solvent casting methods using N,N-Dimethylacetamide (DMAC) and characterized PLA reinforced with cellulose nanofibrils resulted in no improvement in tensile strength (30 MPa compared with pure 
PLA) and percent elongation (2.5\% compared with pure PLA) of the composites. The authors attributed this to the poor interfacial bonding between cellulose nanofibrils and the PLA marix. Addition of PEG to the blend of PLA resulted in significant improvement in tensile strength (28.2\%) and percentage elongation (25\%) compared to pure PLA. The authors posited that PEG covers the surface of the cellulose nanofibrils and act not only as a plasticizer for PLA to improve its elongation, but also as a compatibilizer between the hydrophobic PLA and the hydrophilic cellulose nanofibrils. It was also evident that PEG also prevents the aggregation of the nanofibrils, so that the cellulose nanofibrils disperse in the PLA matrix homogeneously to form a network structure. It was also noted by the authors that the optimum composition of cellulose nanofibils to obtain the best properties was $3 \%$ above which tensile strength and percentage elongation decreased. The FT-IR analysis shows that PEG improved the intermolecular interaction, which is based on the existence of intermolecular hydrogen bonding among PLA, PEG, and cellulose nanofibrils.

\subsection{Cellulose Based Composites}

Cellulose from agricultural products have been identified as a source of biopolymer that can replace petroleum polymers. Green nanocomposites have been successfully produced from cellulose acetate (CA), triethyl citrate (TEC) plasticizer and organically modified clay via melt compounding [41]. The cellulosic plastic with $80 \mathrm{wt} \%$ pure cellulose acetate and $20 \mathrm{wt} \%$ triethyl citrate plasticizer was used as the polymer matrix for nanocomposite production. Mechanical properties of the composites were determined and correlated with observations from X-ray diffraction and transmission electron microscopy. Results show that Cellulosic plastic-based nanocomposites containing 5 and $10 \mathrm{wt} \%$ organoclay have better exfoliated and intercalated structure than those of $15 \mathrm{wt} \%$ organoclay. Tensile strength and modulus of cellulosic plastic reinforced with $10 \mathrm{wt} \%$ organoclay improved by 75 and 180\% respectively. Thermal stability of the cellulosic plastic also increased.

Recently, a cellulose based nanocomposite material has been investigated as a flexible humidity and temperature sensor [42]. Cellulose was obtained from cotton pulp via acid 
hydrolysis using a solution of Lithium chloride and N,N-dimethylacetamide. Nanoscaled polypyrrole was used as the second component of the nanocomposite. Nanocomposites were prepared by polymerization induced adsorption process. Nanoscaled polypyrrole were coated on the surface of the cellulose and its influence on the cellulose membrane was characterized by Atomic force microscopy. The authors focused basically on the sensing ability and not the structural integrity of the nanocomposite material. However, the analysis revealed that there was successful deposition of the polypyrrole nanolayer onto the cellulose surface. Because the material was not analyzed on structural basis it could not determined if cellulose served as the reinforcement or the polypyrrole.

An active antimicrobial packaging material has been developed using methyl cellulose (MC) as the base material with montomorillionite (MMT) as reinforcement [43]. MC and MMT were industrially prepared and mixed with Carvacrol (CRV) to form nanocomposites as shown in Figure 1 and the resulting nanocomposite characterized.

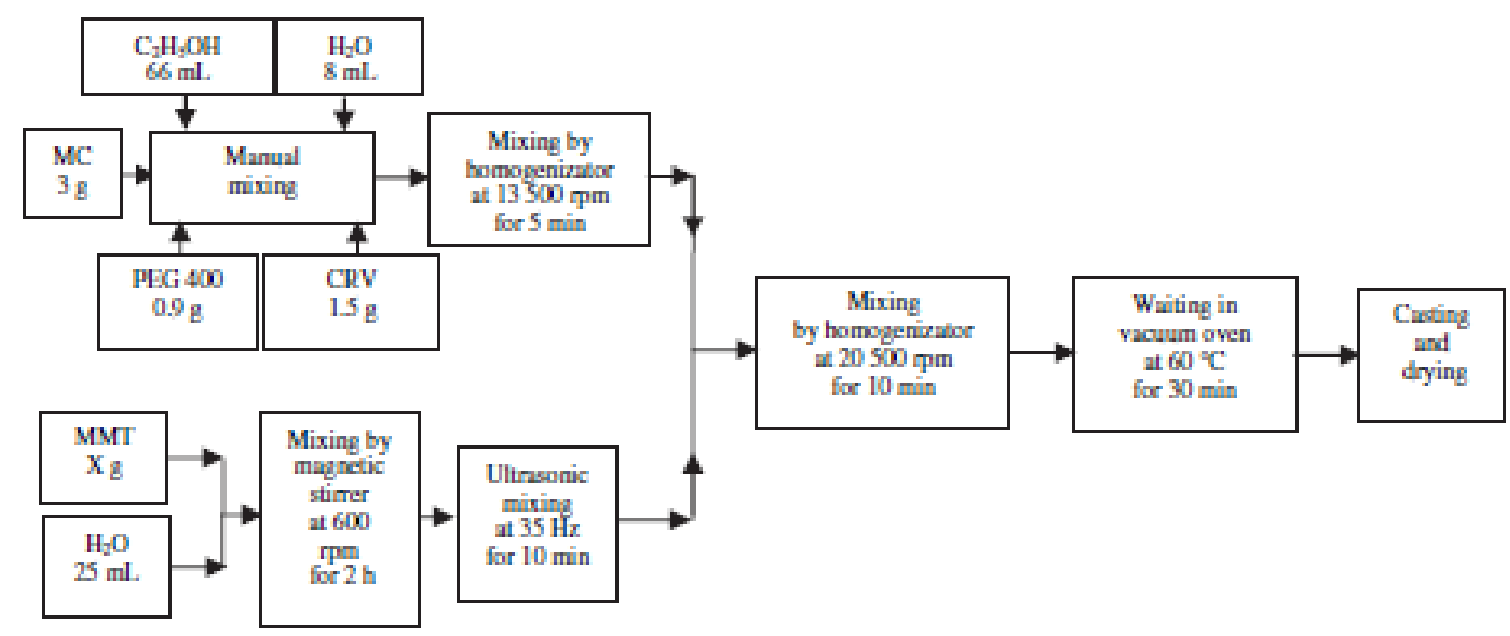

Figure 1. MC/CRV/MMT nanocomposite film preparation procedure.

TEM showed that there were both intercalated and exfoliated nanocomposite structures with exfoliated structures being more prevalent in nanocomposites with low concentration of MMT. Thermal stability of nanocomposite was found to increase with increase in concentration of MMT. The authors posited that the little thermal degradation shown by the nanocomposite is due to the structural degradation of MC at higher 
temperatures. The study did not assess the nanocmposite structurally. Further works in this area includes the works of Zimmermann et al. [44] and Zadagan et al. [45] who evaluated the use of cellulose based nanocomposite with hydroxylapatite for medical applications. Both authors did not analyze their nanocomposite materials structurally providing no basis of comparison with other nanocomposite materials of interest.

\subsection{Plant Oil Based Composites}

Bio-based nanocomposites have been developed from epoxidized soybean oil, diglycidyl ether of bisphenol-A (DGEBA) and organically modified montmorillonite (OMM) [46]. Soy-based epoxy resin (30/70 wt\%) was mixed with different organophilic montmorillonite clay (as reinforcement) concentrations (1 wt\%, $3 \mathrm{wt} \%, 5 \mathrm{wt} \%$ and $7 \mathrm{wt}$ $\%)$ to form nanocomposites using a mechanical stirrer. The tensile strengths of $1 \mathrm{wt} \%, 3$ wt\%, $5 \mathrm{wt} \%$ and $7 \mathrm{wt} \%$ OMM reinforced soy-based epoxy nanocomposites increased by $2 \%, 7 \%, 12.6 \%$ and $23.3 \%$ respectively. Impact strength and flexural properties of the nanocomposites show significant improvement. A maximum increase of $25 \%$ was recorded for flexural strength of the nanocomposites.

Nanocomposites reinforced by exfoliated clay were found to exhibit higher storage moduli. The SEM images of the composites reveal relatively uniform dispersion of organoclay layers in addition to the good interface of the material. The authors argue that improvement of properties is due to proper exfoliation of the nanocomposite. The improvement of both toughness and impact strength in the case of the exfoliated nanocomposites was attributed to the plasticizing effect of the long aliphatic chains in the soy-based epoxy polymer matrix and reinforcement effect of the clay nano-layers.The composite produced is not completely from green source because of the use of organophillic montorillonite clay as reinforcement.

Azeredo et al. [47] had earlier reported the use of mango puree-based edible films for nanocomposites. Nanocomposite were developed by adding cellulose nanofibers (CNF) in different concentrations (up to $36 \mathrm{~g} / 100 \mathrm{~g}$ ) as nanoreinforcement to mango puree based edible films for packaging applications. The study revealed that mango puree 
edible films can be used as matrix material for biocomposites as the tensile strength increased from 4.06 $\mathrm{MPa}$ to 8.09 $\mathrm{MPa}$ and the Young's modulus from 19.85 $\mathrm{MPa}$ to 322.05 MPa. This improvement in properties was attributed to the fact that the nanofibers seem to have presented good interactions with the mango puree. They were found to disperse in the matrix without significant agglomeration. The authors suggested that the interactions may have occurred between cellulose and neutral sugar side chains of the mango pectin.

Soy based polyurethane can be used as a matrix for the production of bio-based nanocomposites [48]. The polyurethane modified with Halloysite Nanotubes (HNT) nanoparticles was used to manufacture E-glass reinforced composites using low cost vacuum assisted resin transfer molding process and characterized for ultimate compressive strength, flexural strength, flexural modulus and interlaminar shear strength (ILSS). Results show that interlaminar shear strength increased with increase in percentage of HNT used (from 14.28MPa for $0 \mathrm{wt} \%$ HNT to $21.28 \mathrm{MPa}$ for $2.4 \mathrm{wt} \%$ HNT). Ultimate compressive strength, flexural modulus and flexural strength did not show appreciable changes. $0.8 \mathrm{wt} \% \mathrm{HNT}$ gave the best combination of properties with 6 percent, 28 percent, and 82 percent increase in flexural strength, flexural modulus and ILSS respectively.

\subsection{Polymer-Polymer Blends Based Composites}

The blending of two or more polymers to achieve a polymer that is biodegradable has also drawn research interest. These polymers have been tested for their degradability and mechanical properties and thus recommended for use as degradable polymers for composite applications. Such polymer blend Starch/PLA blends, poly butylenes succinate/cellulose acetate blends, starch/modified polyester blends, polycarprolactone/poly vinyl alchohol blends and thermoplastic starch/polyesteramide blends [49-54] has been reported.

Recent use of binary and ternary blends of polylactide (PLA), polycaprolactone (PCL) and thermoplastic starch (TPS) as composites has been reported by 
Sarazin et al. [55]. The blends were prepared using a one-step extrusion process. The transition temperatures for TPS/PLA and TPS/PLA and PCL blends were found to be approximately $-57^{\circ} \mathrm{C}$ for blends with $36 \%$ glycerol. Increasing the concentration of TPS in PLA resulted in a corresponding increase in strain at break with decrease in elastic modulus and maximum strength. Natural rubber has also been blended with starch to form nanocomposites [56]. SEM images of the fractured surface of the starch/natural rubber/clay nanocomposite (prepared with unmodified natural rubber latex) loading with $3 \mathrm{wt} \%$ clay (see Figure 2a) revealed that both thermoplastic starch matrix (gray areas) and dispersed rubber phase (white areas) are clearly separated indicating lack of interfacial adhesion. On the other hand, the use of modified natural rubber (see Figure 2b.) resulted in a finer dispersion and improved interfacial adhesion.

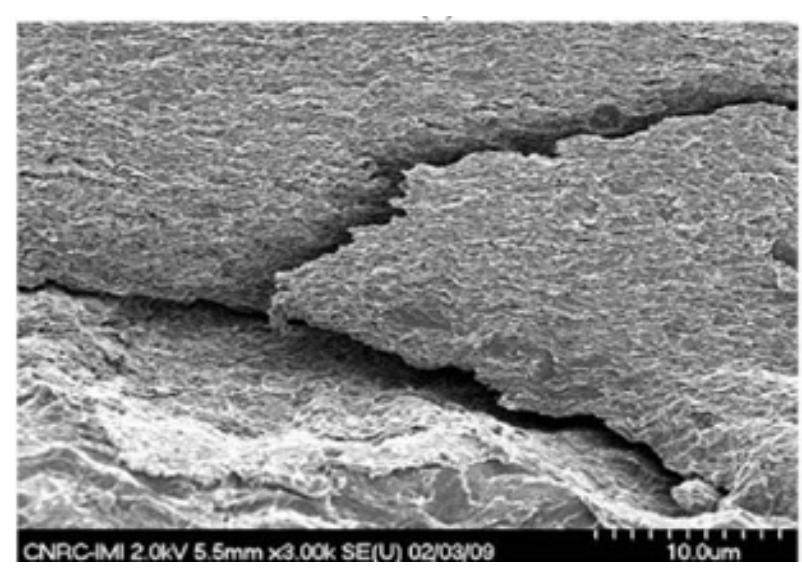

(a)

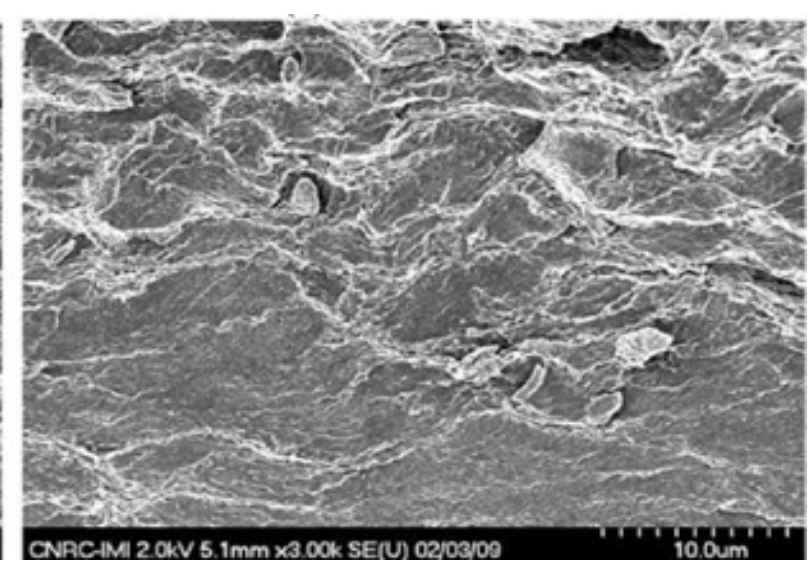

(b)

Figure 2 . SEM micrographs of starch/natural rubber/clay nanocomposites with (a) unmodified natural rubber, and (b) modified natural rubber.

\subsection{Other Biopolymer Based Composites}

Other biopolymers used in nanocomposites synthesized are Polyhydroxyl butyrate (PHB) — a natural occurring polyester produced by numerous bacteria in nature, Gelatin-a biopolymer obtained by thermal denaturation of collagen isolated from animal skin and bones with dilute acid and Chitosan-a natural polymer found in exoskeletons of crustaceans and insects and in the cell wall of fungi and micro organisms [57-60]. Mechanical and water vapor barrier properties of chitosan based nanocomposites were improved by addition of cellulose nanofiber whereas chitosan 
filled with hydroxyapatite, tricalcium phosphate, carbon fiber and montorillionite did not show substantial improvement in mechanical properties.

\section{GREEN FILLERS}

The challenge of green composites extends to the quest of reinforcements that are green and renewable. Cellulose (which gives plant their structural rigidity) is the most abundant renewable fiber in nature. Moreover, they can be produced from agricultural waste which makes it more economically viable than any other source of fibers currently in use. Cellulose fiber has offers an outstanding balance of excellent mechanical properties, low density, safer handling and working conditions compared to synthetic fibers [20,13]. Efforts, in the last few years have been focused on the exploitation of natural fibers as load bearing constituents in composite materials. Table 1 shows the list of natural fibers that have been extracted and their properties. These fibers have been applied as reinforcement for composites and nanocomposites.

Table 1. List of natural fibers and their properties.

\begin{tabular}{|c|c|c|c|c|c|c|}
\hline Fiber source & Treatment & $\begin{array}{l}\text { \% } \\
\text { Cellulose } \\
\text { content }\end{array}$ & $\begin{array}{l}\text { Tensile } \\
\text { Strength } \\
\text { MPa }\end{array}$ & $\begin{array}{l}\text { Elastic } \\
\text { Modulus } \\
\text { GPa }\end{array}$ & $\begin{array}{l}\% \\
\text { Elonga } \\
\text { tion }\end{array}$ & $\begin{array}{l}\text { Refere } \\
\text { nce }\end{array}$ \\
\hline Banana & NS & NS & 779 & 32 & 2 & [61] \\
\hline Cotton & $\begin{array}{l}\text { Alkaline boiling } \\
\text { modified with } \\
\text { carbomethylcell } \\
\text { ulose }\end{array}$ & NS & NS & 82 & 13.57 & [62] \\
\hline $\begin{array}{l}\text { Bark of } \\
\text { cotton stalks }\end{array}$ & $\mathrm{NaOH}$ treatment & 79 & 377 & 18.7 & 3.0 & [63] \\
\hline Sisal & NS & NS & $600-700$ & 38 & 2.3 & [64] \\
\hline Flax & NS & NS & $\begin{array}{l}800- \\
1500\end{array}$ & $60-80$ & $1.2-1.6$ & [64] \\
\hline Hemp & NS & NS & 550-900 & 70 & 1.6 & [64] \\
\hline Jute & NS & NS & $400-800$ & $10-30$ & 1.8 & [64] \\
\hline $\begin{array}{l}\text { Coir } \\
\text { (coconut } \\
\text { husk) }\end{array}$ & NS & NS & 220 & 6 & $1.5-2.5$ & [64] \\
\hline Velvet Leaf & $\begin{array}{l}\text { Alkaline } \\
\text { treatment }\end{array}$ & 69 & $325-500$ & $18-38$ & $1.6-2.6$ & [65] \\
\hline
\end{tabular}




\begin{tabular}{|c|c|c|c|c|c|c|}
\hline $\begin{array}{l}\text { Switch grass } \\
\text { leaves }\end{array}$ & $\begin{array}{l}\text { Simple alkaline } \\
\text { treatment }\end{array}$ & 61.2 & 715 & 31 & 2.2 & [65] \\
\hline $\begin{array}{l}\text { Switch grass } \\
\text { stems }\end{array}$ & $\begin{array}{l}\text { Simple alkaline } \\
\text { treatment }\end{array}$ & 68.2 & 351 & 9.1 & 6.8 & [66] \\
\hline $\begin{array}{l}\text { Stinging } \\
\text { nettle }\end{array}$ & NS & NS & 1594 & 87 & 2.11 & [67] \\
\hline Kenaf & $\begin{array}{l}\text { Alkaline } \\
\text { treatment }\end{array}$ & NS & 130 & 11 & 1.3 & [68] \\
\hline Ramie & Untreated & 68.6-76.2 & 560 & 24.5 & 2.5 & [69] \\
\hline $\begin{array}{l}\text { Soybean } \\
\text { straw }\end{array}$ & $\begin{array}{l}\text { Alkaline } \\
\text { treatment }\end{array}$ & 85 & 351 & 12 & 3.9 & [70] \\
\hline Flax & NS & NS & 1339 & 54 & 3.27 & [71] \\
\hline $\begin{array}{l}\text { Wheat } \\
\text { straw }\end{array}$ & $\begin{array}{l}\text { Mechanical } \\
\text { processing }\end{array}$ & 47.55 & 58.7 & 3.7 & NS & [72] \\
\hline $\begin{array}{l}\text { Wheat } \\
\text { straw }\end{array}$ & $\begin{array}{l}\text { Microbial } \\
\text { retting }\end{array}$ & NS & 139.9 & 4.8 & NS & [73] \\
\hline $\begin{array}{l}\text { Wheat } \\
\text { straw }\end{array}$ & $\begin{array}{l}\text { Chemical } \\
\text { processing }\end{array}$ & 63.14 & 146 & 7.9 & NS & [74] \\
\hline Hop stem & $\begin{array}{l}\text { Alkaline } \\
\text { treatment }\end{array}$ & 84 & 53.3 & 20 & 3.3 & [74] \\
\hline Cornstalks & $\begin{array}{l}\text { Alkaline } \\
\text { treatment }\end{array}$ & 52 & 286 & 16.5 & 2.2 & [75] \\
\hline
\end{tabular}

NS: Not specified

The use of natural fiber in the production of composites in the early 90's was largely seen in the use of steam exploded hemp fiber as reinforcement in polypropylene-based composites [76]. Hemp fibers were first purified by steam explosion in a flash hydrolysis laboratory pilot unit. It was then compounded directly with polypropylene and after surface treatment with propylene maleic anhydride co-polymer. Microstructural and tensile properties were studied with a SEM and Instron tensile testing machine respectively. The steam exploded fiber was had a cellulose content of 55\%. Slight increase in strength was noticed in the treated fiber reinforced composite at a higher filler content, strength of untreated fiber reinforced composites decreased in because of poor adhesion between fiber and the matrix. The percentage elongation generally decreased with increase in fiber content, while tensile modulus increased with percentage of fiber in the polymer. Treated fiber reinforced composites had the highest modulus. A similar 
study on bamboo fiber [77] show that $20 \%$ of fiber in propylene matrix led to 12.5 and $10 \%$ increase in flexural and tensile strengths respectively.

The use sisal, kenaf, hemp, jute and coir fibers as reinforcement in polypropylene based composites were investigated by [64]. The fibers were reinforced in polypropylene by compression moulding using a film stacking method. Tensile testing was on Instron tensile test machine. The elastic modulus, failure strain and tensile strength were calculated from the stress strain curve. Flexural tests were also performed with the same machine using three point bending technique. Impact tests were performed on an Instron charpy impact testing machine. Results show that hemp fiber composites displayed the highest tensile strength (52 MPa) while coir has the lowest (about $10 \mathrm{MPa}$ ). The strength of kenaf, sisal and jute composites was approximately $30 \mathrm{MPa}$. Hemp composites were showed the best flexural strength (54 MPa). This compares well with glass mat composites (60 MPa). The tensile modulus of coir composites was $1.3 \mathrm{GPa}$ while that of hemp and kenaf composites was approximately 6.8 GPa. Mechanical properties of natural fiber composites tested compared favourably with corresponding glass mat composites and could be used in many applications that require high load bearing capabilities.

A similar study was conducted on the use of chemically modified banana fiber reinforced in polyester resin [61]. Previously extracted cellulose fibers from banana plant were collected and treated with two types of silanes (A174 and A151) and used to make composites with polyester as the matrix material (40\% fiber content). Mechanical properties of the fiber and composites were determined with a dynamic mechanical analyzer. Scanning electron microscope was used to examine the microstructure of both modified and fractured composites. The storage modulus of the composites was found to be temperature dependent with a sharp decrease between 80 and $90{ }^{\circ} \mathrm{C}$ followed by a modulus plateau at higher temperatures. Treatment of fiber led to improved mechanical properties.

The study on the potential of wheat straw fibers prepared by mechanical and chemical processes as reinforcing additives for thermoplastics was carried out by Panthapulakkal et al. [73]. Composites of polypropylene filled with $30 \%$ wheat straw fibers were 
prepared and their mechanical properties evaluated. The fibers were processed chemically using $\mathrm{NaOH}$ pulping and mechanically using a laboratory scale refiner. Composites with mechanically prepared wheat straw fibers yielded $29 \%$ and $49 \%$ improvement in tensile and flexural strength whereas those with chemically processed fibers exhibited $12 \%$ and $49 \%$ enhancement. It is expected that the chemically processed fiber would exhibit higher strength and modulus because they were more homogeneous, stronger and longer than the mechanically processed fibers. This the authors attributed to poor dispersion of the cellulose rich chemically processed fibers, which resulted in a strong interaction between the hydrophilic hydroxyl groups of cellulose. The poor dispersion was attributed to the production process. It is the position of the authors that full potential of the reinforcement could be achieved by proper dispersion of the chemically treated fibers but did not specify the process that would lead to proper dispersion.In another study, a series of environmentally friendly glycerol plasticized starch (PS) biocomposites were prepared using 0-40 wt\% ramie cellulose nanocrystalites (RN) as fillers [18]. The ramie cellulose nanocrystalites, with lengths of $538.5 \pm 125.3$ $\mathrm{nm}$ and diameters of $85.4 \pm 25.3 \mathrm{~nm}$ on average, were prepared from ramie fibers by acid hydrolysis. Different fractions of RN were used to form composites with the glycerol plasticized starch. The morphology, thermal behavior and mechanical properties of the resulting composites were investigated by scanning electron microscopy, differential scanning calorimetry, thermogravimetric analysis, dynamic mechanical thermal analysis and tensile testing. Results reveal that there are synergistic interactions between fillers and between filler and PS matrix and these plays a key role in reinforcing the composites. Tensile strength and Young's modulus of the PS/RN composites, conditioned at 50\% relative humidity, increased from 2.8 MPa to 6.9 $\mathrm{MPa}$ and from 56 MPa to $480 \mathrm{MPa}$ respectively as RN content increases from 0-40 wt\% but the elongation at break decreased from $94.2 \%$ to $13.6 \%$.

Green composites using fibers as a structural material have been developed [78]. Polylactic acid (PLA), L-polylactide acid (PLLA), poly 3-hydroxylbutyrate (PHB), polycaprolactone and starch thermoplastic, poly butylene succianate (PBS) and poly butylene adipate-co-terephtalate (PBAT) were used as matrix. The composites were produced using a film stacking technique. Test samples were cut out from the composites to study their mechanical properties under tensile loading conditions. These tensile 
properties were then compared to those of similar polypropylene flax composites. Young's modulus of a PLLA/flax fiber composite increased from $3321 \mathrm{MPa}$ (neat polymer) to $9519 \mathrm{MPa}$ (30\% flax fiber volume fraction) and the ultimate stress increased from 60 to $99 \mathrm{MPa}$. The strain to failure reduced from 2.4\% to 1.5\%. With the same fiber volume fraction (30\%) Young’s modulus for the PLLA composite was $9519 \pm 481 \mathrm{MPa}$.

A study of the synthesis and mechanical properties of new series of green composites involving Hibiscus sabdariffa fiber as a reinforcing material in urea-formaldehyde (UF) resin based polymer matrix has been reported by Singha and Thakur [79]. Reinforcement of the resin with the fiber was accomplished at three different levels: particle size, short fiber and long fiber by employing optimized resin. Static mechanical properties (tensile, compressive and wear properties) of randomly oriented intimately mixed Hibiscus sabdariffa fiber reinforced polymer composites were investigated as a function of fiber loading using a computerized Universal Testing Machine. Scanning electron microscopy was used to examine the morphology of the resulting composites. It was observed that composites with particle reinforcement show higher tensile properties, followed by short fiber and long fiber. The load bearing capacities are $332.8 \mathrm{~N}$ at extension $2.2 \mathrm{~mm}, 307.6$ $\mathrm{N}$ at extension $2.23 \mathrm{~mm}$ and $286.1 \mathrm{~N}$ at $2.28 \mathrm{~mm}$ extension respectively for particle, short and long fiber reinforced composites. Similar trend was observed for compressive strengths and wear resistances. SEM images show uniform mixing in particle reinforced composite as compared to short and long fiber reinforcement. Thus Hibiscus sabdariffa fiber has immense scope in the production of natural fiber reinforced polymer composites for a variety of industrial applications.

The development of novel nanocomposites using cellulose nanofibers (CNF) in different concentrations (up to $36 \mathrm{~g} / 100 \mathrm{~g}$ ) as nano-reinforcement in mango puree-based edible films for packaging applications have been reported [47]. The effect of CNF was studied in terms of tensile properties, water vapor permeability, and glass transition temperature $\left(T_{\mathrm{g}}\right)$ of the nanocomposite films using standard methods. CNF increased tensile strength from 4.06 to 8.09 MPa, and Young's modulus from 19.85 to $322.05 \mathrm{MPa}$, especially at higher concentrations, which suggest the formation of a fibrillar network within the matrix. The water vapor permeability significantly decreased when CNF was 
incorporated at loadings of at least $10 \mathrm{~g} / 100 \mathrm{~g}$. The effect of the filler on glass transition temperature was low but significant.

Kenaf fiber bundles having 50-150 $\mu \mathrm{m}$ diameters were used to make unidirectional composites materials with emulsion type polylactic acid resin moulded at $180{ }^{\circ} \mathrm{C}$ [80]. The resulting composite was characterized for structural, thermal and mechanical properties using standard methods. The tensile strength of the composite decreased when kept at 1 for 60 minutes. The unidirectional fiber reinforced composite has the highest tensile (223 MPa) and flexural strengths (254 MPa) at 70\% fiber content. Tensile and flexural strengths and elastic moduli of the composites increased linearly up to 50\%.

Recently, natural cellulose obtained from the bark of cotton stalks have been used to develop composites [63]. Cellulose fibers were extracted from cotton stalks using simple alkaline extraction. The reinforcing fibers were carded (separated) and compression molded with polypropylene matrix to form composites and then tested for tensile properties on an Instron tensile tester. Polypropylene composites reinforced with the fibers had a flexural strength of 12.4 MPa, an offset yield of 22.5 MPa, stiffness of 1.4 $\mathrm{N} / \mathrm{mm}$, modulus of elasticity of $502 \mathrm{MPa}$, tensile strength of $15.7 \mathrm{MPa}$, tensile modulus of $806 \mathrm{MPa}$ and an impact resistance of $0.3 \mathrm{~J}$. The fiber had a single cell length of 2.1 mm and a width of $9.7 \mu \mathrm{m}$.

Reddy [81] went further to investigate natural cellulose fibers from milkweed stem using simple alkaline treatment. The amount of cellulose in the fibers was determined as the acid detergent fiber according to AOAC method. The physical structure of the fibers in terms of percentage crystallinity, shape and position of the cellulose peaks were observed using an X-ray diffractometer. An SEM with variable pressure was used to observe the morphological features of the fibers. Tensile properties in terms of breaking tenacity, percentage breaking elongation and Young's modulus were determined using Instron tensile testing machine. Results obtained showed that milkweed stem yielded $75.4 \%$ cellulose of $0.9 \mathrm{~mm}$ average length single cells and diameter of $13.0 \mu \mathrm{m}$. Fibers obtained had crystallinity of 39\%, and breaking elongation of 4.7\%. A modulus of $122 \mathrm{~g} /$ denier (15.8 GPa) was also reported for the fibers. The milkweed stem fibers properties are 
found similar to that of common fibers like cotton and linen and are suitable for textile, composite, automotive and other fibrous applications.

The influence of wheat bran content as fillers in biodegradable composites based on cassava starch containing glycerol and potassium sorbate was examined by Famá et al. [21]. Composite Films were produced by casting using three different fractions of wheat bran fiber: $1.5 \mathrm{mg}, 13.5 \mathrm{mg}$ and $27.1 \mathrm{mg} / \mathrm{g}$ of matrix. Mechanical properties of the resulting composites were evaluated using dynamic and quasi static test. Physical properties were also investigated. The study revealed that the mechanical properties of starch-wheat bran composites were improved when the content of the fiber was increased. The storage modulus and hardening of the films increased but maintained high deformation to rupture (beyond 70\%). This reinforcing effect was attributed, to the high storage modulus of wheat bran due to its water-insoluble fiber content. On the other hand the composites showed a decrease in the moisture content, with increase in bran content. Thus increase in the wheat bran content produces an improvement in water vapor barrier properties.

Kaushik et al. [22] recently reported research on green nanocomposite using natural polymers and agro waste cellulose fibers. The novel nanofibril/thermoplastic starch (TPS) based nanocomposites were made with nanofibers from wheat straw and plasticized maize starch. The cellulose nanofibrils were extracted using steam explosion, acidic treatment and high shear mechanical treatment and dispersed in thermoplastic starch (TPS) using a high shear mixer in varying proportions. The resulting composite was analyzed for morphology, thermal and mechanical properties using standard methods. The nanocomposite showed the highest tensile modulus (about $220 \mathrm{MPa}$ ) at 15\% fiber content and the highest yield strength (about $6.5 \mathrm{MPa}$ ) at that same fiber content. A scanning electron microscope image of $10 \%$ nanofiber in thermoplastic starch showed dispersed nanofibers in the matrix (see Figure 3). 


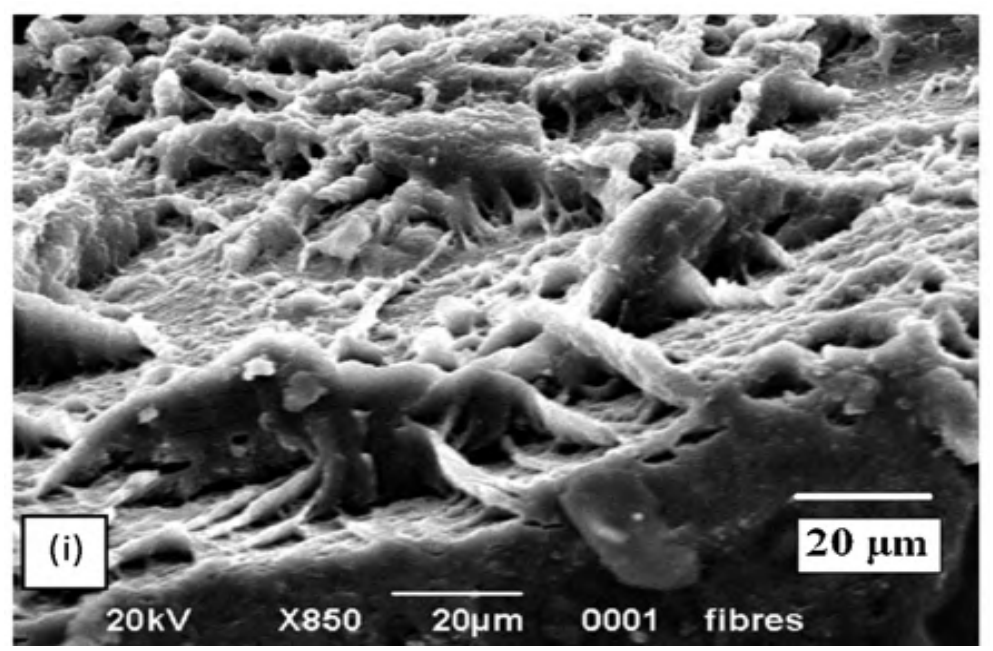

Figure 3 . SEM image of starch cellulose nanofibril nanocomposites with $10 \%$ cellulose nanofibrils.

Polylactic acid and cellulose fibrils nanocomposites have been developed by Qu, et al. [40]. Bleached wood pulp was used as the fiber and commercial grade polylactic acid as the matrix. A chemo-mechanical method was used to prepare cellulose nanofibrils which were dispersed uniformly in an organic solvent. Polyethylene glycol (PEG) was added to the matrix as a compatibilizer to improve the interfacial bonding between the matrix and the fiber. The composites were obtained by solvent casting methods from $\mathrm{N}, \mathrm{N}$ Dimethylacetamide (DMAC) and characterized. After adding cellulose nanofibrils to the PLA matrix, the composite has tensile strength of $30 \mathrm{MPa}$ with $2.5 \%$ elongation which is lower than that of pure PLA. Addition of PEG to the blend of PLA and cellulose nanofibrils resulted in a significant improvement in tensile strength and \% elongation of the composites. The tensile strength and the elongation (of PLA + PEG + nanofibrils) increased by $28.2 \%$ and 25\%, respectively, compared with pure PLA, and increased by $56.7 \%$ and $60 \%$ compared with the PLA/cellulose nanofibrils. The FT-IR analysis showed an improvement in the intermolecular interaction, which is based on the existence of intermolecular hydrogen bonding among PLA, PEG, and cellulose nanofibrils.

Starch composites reinforced by bamboo cellulosic crystals were produced by Liu et al. [23]. Bamboo cellulose crystals (BCCs) were prepared by Combined $\mathrm{HNO}_{3}-\mathrm{KClO}_{3}$ 
treatment and sulphuric acid hydrolysis and used to reinforce glycerol plasticized starch. The structure and morphology of BCCs were investigated using X-ray diffraction, electron microscopy, and solid-state 13C NMR while tensile properties of the composites were determined using Instron Tensile machine. Results show that BCCs were of typical cellulose I structure (50-100 nm in diameter). The morphology of BCCs depends on its concentration in the suspension. The elongation at break increased as BCC content decreased. It was also observed that incorporation of a significant quantity of cellulose crystals cause the resulting composites to exhibit a high relaxation peak.Finally, BCCs at the optimal 8\% loading level exhibited a higher reinforcing efficiency for plasticized starch plastic than at any other loading level.

Guimarães, et al. [24] have reported the use of corn starch with banana and sugarcane fibers for the production of green composites. Commercial grade starch (about 28\% amylose) was obtained from corn while fibers were obtained from banana pseudo stem and sugarcane bagasse via chemo mechanical method. Composites were fabricated by mixing laminates of starch and fibers in a ball mill. X-ray diffractometer was used to determine the crystallinity of starch and its composites. Tensile test was performed on an Instron tensile testing machine to obtain stress-strain curves. The resulting composites had good thermal stability, while fractographic studies of $70 \mathrm{wt} \%$ starch and $30 \%$ glycerol matrix revealed cracks between smooth and rough surface and dimples in rough regions, suggesting the sample was ductile. The Young's modulus increased by 186\%, $294 \%$ and $201 \%$ over the matrix for banana fiber contents of $20 \%, 25 \%$ and $35 \%$, respectively, in the starch + glycerol matrix. The ultimate tensile strength (UTS) remained relatively constant. The yield strength (YS) increased by about 129\%, 141\% and 133\% for 20, 25 and 35 wt\% fiber contents, while the elongation (\%) decreased about fivefold for $20 \mathrm{wt} \%$, sixfold for $25 \mathrm{wt} \%$ and sevenfold for $35 \mathrm{wt} \%$ fiber content. The researchers attributed the remarkable change in yield strength and Young's modulus to the compatibility (both chemical and structural) between the reinforcements (cellulose chains) and the starch-glycerol matrix. They also posited that Improvement in Young's modulus can also be attributed to the deplastification of starch caused by the partition of glycerol between the constituents of the composites (matrix and fibers). 


\section{NANOCOMPOSITES PROCESSING METHODS}

Many methods have been employed for the production of nanocomposites in an attempt to achieve optimum dispersion of fibers in the matrix.

Extrusion followed by injection molding has been used [82,83]. Although the effect of the method on the properties of the resulting composite has not been reported, it is believed that the process method leads to better exfoliation of fibers in the matrix. Melt extrusion is another method frequently been used [56,16]. Majdzadeh [56] noted that in the use of this method, extrusion speed has a significant effect on the thermal properties, specific energy requirement, radial expansion ratio and compressibility of polymer foams. Another common method is film stacking which involves compressing a stack of polymer film and fiber for a period of time. It has been reported that this moulding method has a profound impact on the tensile properties of the composites [78]. Some other workers have used melt compounding followed by compression moulding [84,76], injection moulding [85] solution casting after gelatinization [21,23], direct melting and solidification [86] and one step in-situ intercalative solution polymerization [87]. The one step in-situ polymerization method involves the dispersion of nanofillers in monomer(s), followed by bulk or solution polymerization. The nanofillers are always modified by functional groups to increase the interaction between the polymers and the nanofillers, or to get a good dispersion in the polymer matrix. This method has been reported to have many advantages, such as ease of handling and better performance of the final products $[88,89]$.

\section{CHALLENGES}

The greatest challenge in the making of nanocomposites over the past decade has been the compatibility of the hydrophobic (water repelling) polymer matrix and hydrophilic (water absorbing) fibers which result in non-uniform dispersion of fibers within the matrix and poor mechanical properties [13,90]. To improve the affinity and adhesion between fibers and thermoplastic matrices in composites production, additives such as chemical coupling agents or compatibilizers (Maleated polyethylene (MAPE), 
carboxylated polyethylene (CAPE), titanium derived mixture (TDM), Maleic anhydride polypropylene (MAPP), corono discharge), calendaring, stretching, thermo treatment, reaction with methanolmelamine, isocyanates, triazine, silane and mercerization of the matrix have been employed [11,39,40,74,84,86,91-93] with no significant result. A better understanding of the molecular structure and interfacial interaction between the matrix and the fibers and the relationship between the structure and property would be a major breakthrough in this area of research.

Another challenge of interest is the quest for true green polymers with good mechanical properties to be used as matrix material. Biopolymers such as starch have poor water resistance, inferior tensile properties and are highly brittle due to their large particle size which necessitates the use of plasticizers such as glycerol in the presence of heat and pressure $[49,94]$. No significant result has been recorded apart from ductility imparted by the plasticizers. Moreover, it is noted that the use of plasticizers in starch leads to the presence of residual sugar in the matrix which impairs its adhesion properties to natural fillers [85]. On the other hand PLA have unique properties such as high mechanical strength, low toxicity and good barrier properties [6]. However, PLA composites are limited in applications due to its low glass transition temperature, weak thermal stability, low ductility and toughness and low modulus above the glass transition temperature [95]. Generally, modifiers have been used to improve stiffness at elevated temperatures, reduce cost and increase the degradation rate [6]. PLA is the most promising of all the biopolymers currently in use and require much attention. Other biopolymer sources such as cellulose, gelatin, chitosan and plant-based oils are more scarce sources and involve a more tedious and costly production process.

In nanotechnology it is necessary to separate filler particles into the right shape and layer structure. To achieve maximum properties these particles need to be very thin (one nanometer) and very wide (500 nanometers). Achieving this is an enormous task and requires sophisticated machines such as high pressure homogenizers and inline dispersers. Although recent technology has made this possible, it has been observed that efforts to attain nanosize particles produce wide size ranges result which gives rise to inconsistencies [22,43]. In addition, particle orientation has effect on the tensile 
properties of nanocomposite materials. It is difficult to take the orientation of nanosize fibers into consideration but in macromechanics it has been observed that the orientation of the fibers have an overiding effect on the mechanical properties of the composite material. How to achieve proper orientation of particles in the matrix is already being examined [96]. Besides there is a possibility of reaggregation - where the particles are lumped together. This is a function of the processing method and its prevention must be taken into consideration when processing the nanocomposites.

\section{PROSPECTS AND APPLICATIONS}

Nanocomposites have been used in several applications such as mirror housings on various vehicle types, door handles, door panels, trunk liners, instrument panels, parcel shelves, head rests, roofs, upholstery and engine covers and intake manifolds and timing belt covers. Other applications currently being considered include impellers and blades for vacuum cleaners, power tool housings, mower hoods and covers for portable electronic equipment such as mobile phones, pagers etc [1,11]. Its excellent barrier properties, chemical resistance and surface appearance make it an excellent material for packaging applications such as in beer and carbonated drinks bottles and paperboard for fruit juice and dairy. Nanocomposites also have future in aerospace applications because of their light weight.

\section{CONCLUSIONS}

Natural fiber reinforced composites using biodegradable polymer as matrix are considered as most environmentally friendly material. The making of novel polymers with inherent environmentally favorable properties such as renewability and degradability, a series of interesting polymers have been realized through multiple research activities ranging from thermoplastic starch and its blends, PLA and its modifications, cellulose, gelatin, chitosan, etc. Natural fiber being preferred over synthetic fibers for environmental reasons has also been synthesized from agricultural sources such as kenaf, jute, hemp, flax, banana, bamboo, sisal and coconut coir, etc. There is thus a wide range of possible applications of nanocomposites. However, the 
many problems of poor adhesion of matrix and fiber, difficulty of fiber orientation, the achievement of nanoscale sizes and the evolution of truly green polymers, which will be environmentally friendly and renewable, must first be solved.

\section{REFERENCES}

[1.] Hay, J.N.; Shaw, S.J. Nanocomposites—properties and applications. Available online: http://www.azom.com/Details.asp?ArticleID=921 (accessed on August 15, 2010)

[2.] Njuguna, J.; Pielichowski, K.; Desai, S. Nanofiller-reinforced polymer nanocomposites. Polym. Adv. Technol. 2008, 19, 947-959.

[3.] Leja, K.; Lewandowicz, G. Polymer biodegradation and biodegradable polymers—a review. Polish J. Environ. Stud. 2010, 19, 255-266.

[4.] TPA Plast global Engineering Nanocomposite polymers. http://www.tpacomponents.com/uploads/pdf/en/0305_EN.pdf (accessed on 20 August 2010).

[5.] Drzal, L.T. Sustainable Biodegradable Green Nanocomposites from Bacterial Bioplastic for Automotive applications. http//www.egr.msu.edu/cmsc/biomaterials/index.html (accessed on 20 August 2010).

[6.] Jamshidian, M.; Tehrany, E.A.; Imran M.; Jacquot M.; Desobry S. Poly-lactic acid: Production, applications, nanocomposites, and release studies. Compr. Rev. Food Sci. Food Saf. 2010, 9, 552-571.

[7.] Amass, W.; Amass, A.; Tighe, B.A review of biodegradable polymers: Uses, current developments in the synthesis and characterization of biodegradable polyesters, blends of biodegradable polymers and recent advances in biodegradation studies. Polym. Int. 1998, 47, 89-144.

[8.] Chandra, R.; Rustgi, R. Biodegradable polymers. Prog. Polym. Sci. 1998, 23, 1273-1335.

[9.] Mohanty, A.K.; Misra, M.; Hinrichsen, G. Biofibres, biodegradable polymers and biocomposites: An overview. Macrmol Mater Eng. 2000, 276/277, 1-24. 
[10.] Siracusa, V.; Rocculi, P.; Romani, S.; Rosa, M.D. Biodegradable polymers for food packaging: a review. Trends Food Sci. Technol. 2008, 19, 634-643.

[11.] Pandey, J.K.; Chu, W.S.; Lee, C.S.; Ahn, S.H. Preparation characterization and performance evaluation of nanocomposites from natural fiber reinforced biodegradable polymer matrix for automotive applications. Presented at the International Symposium on Polymers and the Environment: Emerging Technology and Science, BioEnvironmental Polymer Society (BEPS), Vancouver, WA, USA, 17-20 October 2007.

[12.] Sinha, S.R.; Bousmina, M. Biodegradable polymer/layered silicate nanocomposites. In Polymer Nanocomposites; Mai, Y., Yu, Z., Eds.; Woodhead Publishing and Maney Publishing: Cambridge, England, pp. 57-129.

[13.] John, M.J.; Thomas, S. Biofibres and biocomposites. Carbohyd. Polym. 2008, 71, 343-364.

[14.] Carvalho, A.J.F.; Curvelo, A.A.S.; Agnelli, J.A.M.A. First insight on composites of thermoplastic starch and kaolin. Carbohyd. Polym. 2001, 45, 189-194.

[15.] Pandey, J.K.; Singh, R.P. Green nanocomposites from renewable resources: Effect of plasticizer on the structure and material properties of clay-filled starch. Starch/Stärke 2005, 57, 8-15.

[16.] Guan, J.; Hanna, M.A. Selected morphological and functional properties of extruded acetylated starch-cellulose foams. Bioresource Technol. 2006, 97, 17161726.

[17.] Kumar, A.P.; Singh, R.P. Biocomposites of cellulose reinforced starch: Improvement of properties by photo-induced crosslinking. Bioresource Technol. 2008, 99, 8803-8809.

[18.] Lu, Y.; Weng, L.; Cao, X. Morphological, thermal and mechanical properties of ramie crystallites-reinforced plasticized starch biocomposites. Carbohyd. Polym. 2006, 63, 198-204.

[19.] Ma, X.F.; Yu, J.G.; Wang, N. Fly ash-reinforced thermoplastic starch composites. Carbohyd. Polym. 2007, 67, 32-39.

[20.] Svagan, A. Bio-inspired cellulose Nanocomposites and foams based on starch matrix. PhD thesis, Department of Fiber and Polymer Technology, KTH Chemical Science and Engineering, SE-100 44, Stockholm, Sweden, 2008. 
[21.] Famá, L.; Gerschenson, L.; Goyanes, S. Starch-vegetable fiber composites to protect food products. Carbohyd. Polym. 2009, 75, 230-235.

[22.] Kaushik, A.; Singh, M.; Verma, G. Green nanocomposites based on thermoplastic starch and steam exploded cellulose nanofibrils from wheat straw. Carbohyd. Polym. 2010, 82, 337-345.

[23.] Liu, D.; Zhong, T.; Chang, P.R.; Li, K.; Wu, Q. Starch composites reinforced by bamboo cellulosic crystals. Bioresource Technol. 2010, 101, 2529-2536.

[24.] Guimarães, J.L.; Wypych, F.; Saul, C.K.; Ramos, L.P.; Satyanarayana, K.G. Studies of the processing and characterization of corn starch and its composites with banana and sugarcane fibers from Brazil. Carbohyd. Polym. 2010, 80, 130138.

[25.] Kaith, B.S.; Jindal, R.; Jana, A.K.; Maiti, M. Development of corn starch based green composites reinforced with Saccharum spontaneum L fiber and graft copolymers-Evaluation of thermal, physico-chemical and mechanical properties. Bioresource Technol. 2010, 101, 6843-6851.

[26.] Ogata, N.; Jimenez G.; Kawai H.; Ogihara T. Structure and thermal/mechanical properties of poly(L-lactide)-clay blend. J. Polym. Sci. Part B: Polym. Phys. 1997, 35, 389-96.

[27.] Sinha, R.S.; Okamoto, K.; Yamada, K.; Okamoto, M. Novel porous ceramic material via burning of polylactide/layered silicate nanocomposite. Nano Letts. 2002, 2, 423-426.

[28.] Sinha, R.S.; Yamada K.; Okamoto, M.; Ueda, K. New polylactide/layered silicate nanocomposite: A novel biodegradable material. Nano Letts. 2002, 2, 1093-1096.

[29.] Sinha, R.S.; Maiti P.; Okamoto, M.; Yamada, K.; Ueda, K. New polylactide/layered silicate nanocomposites. 1. Preparation, characterization and properties. Macromolecule 2002 35, 3104-3110.

[30.] Sinha, R.S.; Yamada, K.; Ogami A.; Okamoto, M.; Ueda, K. New polylactide layered silicate nanocomposite: Nanoscale control of multiple properties. Macromol. Rapid Commun. 2002, 23, 493-497.

[31.] Sinha, R.S.; Okamoto, M.; Yamada, K.; Ueda, K. New biodegradable polylactide/layered silicate nanocomposites: Preparation, characterization and materials properties. Macromolecules 2002, 35, 659-660. 
[32.] Sinha, R.S.; Okamoto, M.; Yamada, K.; Ueda, K. New polylactide/layered silicate nanocomposites: Concurrent improvement of materials properties and biodegradability. Polymer 2003, 44, 857-866.

[33.] Yamada, K.; Ueda, K.; Sinha, R.S.; Okamoto, M. Preparation and properties of polylactide/layered silicate nanocomposites. Kobunshi Robunshu 2002, 59, 760765.

[34.] Maiti, P.; Yamada, K., Okamoto, M, Ueda, K, Okamoto, K New polylactide/ layered silicate Nanocomposites: role of organoclay. Chem. Mater. 2002, 14, 4654-4661.

[35.] Paul, M.A.; Alexandre, M.; Degee, P.; Calberg, C.; Jerome, R.; Dubois, P. Exfoliated polylactide/clay nanocomposites by in-situ coordination-insertion polymerization. Macromol Rapid Commun 2003, 24, 561-566.

[36.] Lee, J.H.; Park, T.G.; Park, H.S.; Lee, D.S.; Lee, Y.K.; Yoon, S.C.; Nam, J.D. Thermal and mechanical characteristics of poly(L-lactic acid) nanocomposite scaffold. Biomaterials 2002, 24, 2773-2778.

[37.] Chang, J.; An, Y.U.; Cho, D.; Giannelis E.P. Poly (lactic acid) nanocomposites: Comparison of their properties with montmorillonite and synthetic mica (II). Polymer 2003, 44, 3715-3720.

[38.] Bondeson, D.; Oksman, K. Dispersion and characteristics of surfactant modified cellulose whiskers nanocomposites. Compos. Interface. 2007, 14, 617-630.

[39.] Lee, S.; Kang, I.; Doh, G.; Yoon, H.; Park, B.; Wu, Q. Thermal and Mechanical Properties of Wood Flour/Talc-filled Polylactic Acid Composites: Effect of Filler Content and Coupling Treatment. J. Thermoplast. Compos. Mater. 2008, 21, 209223.

[40.] Qu, P.; Gao, Y.; Wu, G.; Zhang, L. Nanocomposites of poly (lactic acid) reinforced with cellulose nanofibrils. BioResources 2010, 5, 1811-1823.

[41.] Misra, M.; Park, H.; Mohanty, A.K.; Drzal, L.T. Injection molded 'Green' nanocomposite materials from renewable resources. Presented at the Global Plastics Environmental Conference, Detroit, MI, USA, 18-19 February 2004.

[42.] Mahadeva, S.K.; Yun, S.; Kim, J. Flexible humidity and temperature sensor based 
cellulose-polypyrrole nanocomposite. Sensor. Actuator. A Phys. 2011, 165, 194199

[43.] Tunç, S.; Duman, O. Preparation of active antimicrobial methyl cellulose/carvacrol/montmorillonite nanocomposite films and investigation of carvacrol release. Food Sci. Technol. 2011, 44, 465-472.

[44.] Zimmermann, K.A.; LeBlanc, J.M.; Sheets, K.T.; Fox, R.W.; Gatenholm, P. Biomimetic design of a bacterial cellulose/hydroxyapatite nanocomposite for bone healing applications. Mater. Sci. Eng. 2011, 31, 43-49.

[45.] Zadegan, S.; Hosainalipour, M.; Rezaie, H.R.; Ghassai, H.; Shokrgozar, M.A. Synthesis and biocompatibility evaluation of cellulose/hydroxyapatite nanocomposite scaffold in 1-n-allyl-3-methylimidazolium chloride. Mater. Sci. Eng. 2011, 31, 954-961.

[46.] Sithique, M.A.; Alagar, M. Preparation and Properties of Bio-Based Nanocomposites from Epoxidized Soy Bean Oil and Layered Silicate. Malaysian Polym. J. 2010, 5, 151-161.

[47.] Azeredo, H.M.C.; Mattoso, L.H.C.; Wood, D.; Williams, T. G.; Avena-Bustillos, R.J.;

Mchugh, T.H. Nanocomposite edible films from mango puree reinforced with cellulose nanofibers. J. Food Sci. 2009, 74, 31-35.

[48.] Tate, J.S.; Akinola, A.T.; Kabakov, D. Bio-based Nanocomposites: An Alternative to Traditional Composites. J. Technol. Stud. 2010, 1, 25-32.

[49.] Ke, T.Y.; Sun, X.Z. Effects of moisture content and heat treatment on the physical properties of starch and poly(lactic acid) blends. J. Appl. Polym. Sci. 2001, 81, 3069-82.

[50.] Uesaka, T; Nakane, K; Maeda, S; Ogihara, T.; Ogata, N. Structure and physical properties of poly(butylene succinate)/cellulose acetate blends. Polymer 2000, 41, 8449-54.

[51.] Kesel, C.D.; Wauven, C.V.; David, C. Biodegradation of polycaprolactone and its blends with poly(vinylalcohol) by micro-organisms from a compost of household refuse. Polym. Degrad. Stab. 1997, 55, 107-113. 
[52.] Averous, L.; Fauconnier, N.; Moro, L. Fringant Blends of thermoplastic starch and polyesteramide: Processing and properties. J. Appl. Polym. Sci. 2000, 76, 1117-1128.

[53.] Willett, J.L.; Shogren, R.L. Processing and properties of extruded starch/polymer foams. Polymer 2002, 43, 5935-5947.

[54.] Martin, O.; Averous, L. Poly (lactic acid): Plasticization and properties of biodegradable multiphase systems. Polymer 2001, 42, 6209-6219.

[55.] Sarazin, P.; Li, G.; Orts, W.J.; Favis, B.D. Binary and ternary blends of polylactide, polycaprolactone and thermoplastic starch. Polymer 2008, 49, 599609.

[56.] Majdzadeh-Ardakani, K.; Sadeghi-Ardakani, Sh. Experimental investigation of mechanical properties of Starch/natural rubber/clay nanocomposites. Digest $J$. Nanomater. Biostruct. 2010, 5, 307-316.

[57.] Maiti, P.; Batt, C.A.; Giannelis, E.P. Renewable plastics: Synthesis and properties of PHB nanocomposites. Polym. Mater. Sci. Eng. 2003, 88, 58-59.

[58.] Zheng, J.P.; Li, P.; Ma, Y.L.; Yao, K.D. Gelatine/montmorillonite hybrid nanocomposite. I. Preparation and properties. J. Appl. Polym. Sci. 2002, 86, 1189-1194.

[59.] Takegawa, A.; Murakami, M.; Kaneko, Y.; Kadokawa, J. Preparation of chitin/cellulose composite gels and films with ionic liquids. Carbohyd. Polym. 2010, 79, 85-90.

[60.] Nunes, M.R.S.; Silva, R.C.; Silva, J.G., Jr.; Tonholo, J.; Ribeiro, A.S. Preparation and morphological characterization of chitosan/clay nanocomposites. In Proceedings of the 11th International Conference on Advanced Materials, Rio de jenero, Brazil, 20-25 September 2009; pp. 20-25.

[61.] Pothan, L.A.; Thomas, S. Polarity parameters and dynamic mechanical behavior of chemically modified banana fiber reinforced polyester composites. Compos. Sci. Technol. 2003,

63 , 1231-1240.

[62.] Zemljic, L.F.; Stenius, P.; Stana-kleinschek, J.; Ribitsch, V. Characterization of cotton fibers modified by carboxymethyl cellulose. Lenzinger Berichte 2006, 85, 68-76. 
[63.] Reddy, N.; Yang, Y.; Properties and potential application of natural cellulose fibers from the bark of cotton stalks. Bioresource Technol. 2009, 100, 3563-3569.

[64.] Wambua, P.; Ivens, J.; Verpoest, I. Natural fibers: Can they replace glass in fiber reinforced plastics? Compos. Sci. Technol. 2003, 63, 1259-1264.

[65.] Reddy, N.; Yang, Y. Characterizing natural cellulose fibers from velvet leaf (Abutilon theophrasti) stems. Bioresource Technol. 2008, 99, 2449-2454.

[66.] Reddy, N.; Yang, Y. Natural Cellulose fibers from switchgrass with tensile properties similar to cotton and linen. Biotechnol. Bioeng. 2007, 97, 1021-1027.

[67.] Bodros, E.; Baley, C. Study of the tensile properties of stinging nettle fibers (Urtica dioica) Mater. Lett. 2008, 62, 2143-2145.

[68.] Batra, S.K. Other long vegetable fibers. In Handbook of Fiber Science and Technology;

Lewi, N.M., Pearce, E.M. Eds.; Marcel Dekker Fiber Chemistry: New York, NY, USA, 1998; Volume 4, p. 727.

[69.] Goda, K.; Sreekala, M.S.; Gomes, A.; Kaji, T.; Ohgi, J. Improvement of plant based natural fibers for toughening green composites-Effect of load application during mercerization of ramie fibers. Compos. Part A Appl. Sci. Manuf. 2006, 37, 2213-2220.

[70.] Reddy, N.; Yang, Y. Natural cellulose fibers from soybean straw. Bioresource Biotechnol. 2009, 100, 3593-3598.

[71.] Baley, C. Analysis of the flax fiber tensile behavior and analysis of the tensile stiffness increase. Compos. Part A Appl. Sci. Manuf. 2002, 33, 939-948.

[72.] Sain, M.; Panthapulakkal, S. Bioprocess preparation of wheat straw fibers and their characterization. Ind. Crops Products 2006, 23, 1-8.

[73.] Panthapulakka, S.; Zereshkian, A.; Sain, M. Preparation and characterization of wheat straw for reinforcing application in injection molded thermoplastic composites. Bioresource Biotechnol. 2006, 97, 265-272.

[74.] Reddy, N.; Yang, Y. Properties of natural cellulose fibers from hop stems. Carbohyd. Polym. 2009, 77, 898-902.

[75.] Reddy, N.; Yang, Y. Structure and properties of high quality natural cellulose fibers from corn stalks. Polymer 2005, 46, 5494-5500. 
[76.] Vignon, M.R.; Dupeyre, D.; Garcia-Jaldon, C. Morphological characterization of steam exploded hemp fibers and their utilization in propylene-based composites. Bioresource Biotechnol. 1996, 58, 203-215.

[77.] Thwe, M.M.; Liao, K. Effects of environmental aging on the mechanical properties

bamboo-glass fiber reinforced polymer matrix hybrid composites. Compos. Part A Appl. Sci. Manuf. 2002, 33, 43-52.

[78.] Bodros, E.; Pillin, I.; Montrelay, N.; Baley, C. Could biopolymers reinforced by randomly scattered flax fiber be used in structural applications? Compos. Sci. Technol. 2007, 67, 462-470.

[79.] Singha, A.S.; Thakur, V.K. Mechanical properties of natural fiber reinforced polymer composites. Bull. Mater. Sci. 2008, 31, 791-799.

[80.] Ochi, S. Mechanical properties of Kenaf fibers and Kenaf/PLA composites. Mech. Mater. 2008, 40, 446-452.

[81.] Reddy, N. Extraction and characterization of natural cellulose fibers from common milkweed stems. Polym. Eng. Sci. 2009, 49, 2212-2217. Available online:

http://fidarticles.com/p/articles/ mi_hb3367/is_11_49/ai_n4510020/(accessed on 17 August 2010).

[82.] Ave'rous, L.; Digabel, F.L. Properties of biocomposites based on lignocellulosic fillers. Carbohyd. Polym. 2006, 66, 480-493.

[83.] Averous, L.; Bouquillon, N. Biocomposites based on plasticized starch: Thermal and mechanical behaviours. Carbohyd. Polym. 2004, 56, 111-122.

[84.] Lei, Y.; Wu, Q.; Yao, F.; Xu, Y. Preparation and properties of recycled HDPE/natural fiber composites. Compos. Part A 2007, 38, 1664-1674.

[85.] Zabihzadeh, S.M. Water uptake and flexural properties of natural Filler/HDPE composites. BioResources 2010, 5, 316-323.

[86.] Teixeira, E.; Pasquini, D.; Antonio, A.S.; Corradini, C.E.; Belgacem, M.N.; Dufresne, A. Cassava baggasse cellulose nanofibrils reinforced thermoplastic cassava starch. Carbohydrate polymers 2009, 78, 422-431.

[87.] Huskic, M.; Igon, M.Z. PMMA/MMT nanocomposites prepared by one-step in situ intercalative solution polymerization. European Polymer Journal 2007, 43, 4891-4897. 
[88.] Zou, H.; Wu, S.S.; Shen, J. Polymer/silica nanocomposites: preparation, characterization, properties, and applications. Chem. Rev. 2008, 108, 3893-3957.

[89.] Wei, L.; Hu, N.; Zhang, Y. Synthesis of polymer-Mesoporous silica nanocomposites. Materials 2010, 3, 4066-4079.

[90.] Ashori, A. Wood-plastic composites as promising green-composites for automotive industries! Bioresource Biotechnol. 2008, 99, 4661-4667.

[91.] Kim, J.P.; Yoon T.-H.; Mun S.P.; Rhee J.M.; Lee J.S. Wood-polyethylene composites using ethylene-vinyl alcohol copolymer as adhesion promoter. Bioresource Biotechnol. 2006, 97, 494-499.

[92.] Rong, M.Z.; Zhang, M.Q.; Liu, Y.; Yang, G.C.; Zeng, H.M. The effect of fiber treatment on the mechanical properties of unidirectional sisal-reinforced epoxy composites. Compos. Sci. Technol. 2001, 61, 1437-1447.

[93.] Qin, C.; Soykeabkaew N.; Xiuyuan N.; Peijs, T. The effect of fiber volume fraction and mercerization on the properties of all cellulose composites. Carbohyd. Polym. 2008, 71, 458-467.

[94.] George, E.R.; Sullivan, T.M.; Park, E.H. Preparation of high moisture content thermoplastic polyester starch. Polym. Eng. Sci. 1994, 34, 17-24.

[95.] Harada, M.; Ohya, T.; Iida, K.; Hayashi, H.; Hirano, K.; Fukuda, H. Increased impact strength of biodegradable poly (lactic acid)/poly (butylenes succinate) blend composites by using isocyanate as a reactive processing agent. J. Appl. Polym. Sci. 2007, 106, 1813-1820.

[96.] Demetrakakes, P. Nanocomposites raise barriers, but also face them: Clay based additives increase the barrier qualities of plastics, but obstacles to commercialization must be overcome. Food \& Drug Packaging, (Available from: http://www.findarticles.com/p/articles/mi m0UQX/is 12 66/ai 96123509 (accessed on 19 October 2010). 